\title{
MODELLING OF THE MICROSEGREGATION IN CMSX-4 SUPERALLOY AND ITS HOMOGENISATION DURING HEAT TREATMENT
}

\author{
M.S.A. Karunaratne, D.C. Cox, P. Carter and R.C. Reed \\ University of Cambridge / Rolls-Royce University Technology Centre, \\ Department of Materials Science and Metallurgy, Pembroke Street, Cambridge CB2 3QZ, UK
}

\begin{abstract}
$\underline{\text { Abstract }}$
Microsegregation in the single crystal superalloy CMSX-4 has been studied using electron probe microanalysis, both in the as-cast condition and afler solution heat trealment. In order to establish the solidification path, a statistical treatment of the data is proposed, which is based upon the local value of the quantity $C_{\mathrm{Ta}}-C_{\mathrm{Re}}$. Using differential scanning calorimetry and by appealing to a database of thermodynamic parameters, it is shown that the solidification path cannot be explained without acknowledging that backdiffusion occurs. Analysis of the microsegregation remaining after progressive heat treatment reveals that the dendritic and interdendritic regions homogenise at different rates, owing to the presence of the eutectic mixture; there is evidence of up-hill diffusion of solutes in the eutectic region during homogenisation. Simple expressions based upon a sinusoidal variation of composition are inadequate for the estimation of homogenisation times. A coupled thermodynamic/kinetic theory is able to explain most of the effects which occur, i.e. incipient melting, enrichment of residual $\gamma^{\prime}$ by Ta, Mo and subsequent $\gamma^{\prime}$ dissolution. Although more work needs to be carried out to better establish the thermodynamic and kinetic parameters required by the model, it is at this stage aiready useful for the assessment of new superalloy compositions and for the design of optimal heat treatments.
\end{abstract}

\section{Introduction}

The turbine blading for gas turbine engines [1] is now commonly cast from nickel-base superalloys in single crystal form, often with intricate channels included so that cooler air can be forced to flow within and along the blades during operation [2-4]. Since the capability for single crystal processing first became available, single crystal compositions have evolved considerably [5]. The addition of heavy elements such as $\mathrm{Ta}, \mathrm{W}, \mathrm{Mo}$ and particularly Re by the alloy designer has conferred considerable solid solution strengthening, with concomitant increases in the high temperature creep resistance. Such developments have, over the past twenty years or so, contributed significantly to a steady increase in the turbine entry temperatures of modern aeroengines, which has averaged about $5^{\circ} \mathrm{C}$ per year [6].
Less well appreciated however, are some disadvantages which have arisen as the single crystal compositions have become wore heavily alloyed. For example, the heat treatment schedules required to homogenise the single crystal blades before they enter service have become longer, with tight control of the temperature/time sequence needed to avoid incipient melting. With this in mind, it is possibly surprising that the optimisation of the heat treatment of single crystal superalloys still involves a significant degree of empiricism. Possibly this is because reliable interdiffusion data pertinent to the superalloys have not been available, particularly for the heavy elements such as Re. Fortunately, this situation has recently been remedied [5] and for this reason it was decided to make a first attempt at developing a numerical model for the heat treatment process. This paper is concerned with CMSX-4, which is a second generation single crystal alloy which is finding widespread application in turbine applications; nonetheless it should be noted that the techniques reported here are quite generic and can therefore be applied to other grades of superalloy. In particular, the numerical model is highly suited to the assessment of experimental alloys, during the alloy design process.

\section{Background}

One should consider briefly the reasons why it is necessary to homogenise turbine aerofoils fabricated from single crystal superalloys, prior to their entering operation in the aeroengine. Single crystal superalloys have compositions with as many as twelve different elements present in significant proportions. On thermodynamical grounds alone one could then reasonably expect the freezing range to be rather wide; in practice however, there is a considerable kinetic contribution which arises as a consequence of the presence of the heavy elements, which do not diffuse rapidly in the solid which forms. For most single crystal compositions the very last stages of solidification occur via one or possibly more eutectic reactions, the nature of which differs from alloy to alloy [7]. These eutectic reactions give rise to a significant fraction of a coarse eutectic mixture, which usually contains a large volume fraction of the $\gamma^{\prime}$ phase. 
In practice therefore a homogenisation heat treatment is required, to prevent the occurrence of incipient melting of the eutectic regions during high temperature service. During this treatment, mass transport by bulk diffusion acts to reduce the scale and extent of the microsegregation and eutectic regions which are inherited from the casting process. Traditionally, the degree of microsegregation has been assumed to vary in a sinusoidal fashion, according to expressions such as $[8,9]$

$$
C\{r, t\}=C_{\circ}+C_{n} \cos \left\{\frac{2 \pi r}{I}\right\} \exp \left\{-\frac{t}{\tau}\right\}
$$

where $C_{o}$ and $C_{n}$ are constants and the time constant for homogenisation, denoted $\tau$ is given by

$$
\tau=\frac{L^{2}}{4 \pi^{2} \tilde{D}}
$$

where $\tilde{D}$ is an interdiffusion coefficient. Diffusion is assumed to occur in one-dimension, over a characteristic distance denoted $L$; for the directional solidification of single crystal alloys it is probably appropriate to equate this to a distance somewhere between the primary and secondary dendrite arm spacing.

It has been suggested, particularly for binary alloys [e.g. 8] and for steels [10], that Equations 1 \& 2 represent a useful first approximation for the way in which the degree of microsegregation changes during heat treatment. However, other studies [e.g. 11] have shown that the agreement with theory is poor. For single crystal superalloys, it would appear that the applicability of this simple approach has not yet been tested in an adequate sense. It should be appreciated that the approximations introduced might invalidate its use for this class of alloy. For example, (i) the assumption that the initial concentration profiles can be represented as sinusoidal waves might be unrealistic, particularly owing to the presence of the second phases or eutectic regions, (ii) the presence of large cross-terms in the interdiffusivity matrix might mean that the interdiffusion of the various elements are in fact coupled, with one of the heavy elements controlling the rate at which homogenisation occurs, and (iii) in practice, diffusion must occur in two or possibly three dimensions. It is then quite possible that a more complicatcd theory is to be preferred.

\section{Experimental Details}

\section{Material}

The CMSX-4 single crystal alloy used for the present work was supplied by Rolls-Royce plc in the as-cast condition, in the form of $10 \mathrm{~mm}$ diameter rods of approximate length $120 \mathrm{~mm}$. These had been directionally solidified according to the methods described in [12], and therefore each rod had a $<001>$ crystallographic direction within a few degrees of its long axis. The chemical composition of one of these bars was determined using Leco CS244/TC436AR furnaces and inductively coupled plasma optical emission spectroscopy (ICP-OES). The results are given in Table I.
Table I The chemical composition of the CMSX-4 material used for the present study.

\begin{tabular}{ccccccccccc}
\hline & Al & Co & Cr & Hf & Mo & Ni & Re & Ta & Ti & W \\
\hline wt\% & 5.7 & 9.5 & 6.4 & 0.09 & 0.7 & Bal. & 2.92 & 6.5 & 1.08 & 6.4 \\
\hline
\end{tabular}

The rods were sectioned into $3 \mathrm{~mm}$ long slices. Each of these was subjected to an isothermal heat treatment at a temperature between $1250^{\circ} \mathrm{C}$ and $1315^{\circ} \mathrm{C}$, in a vacuum furnace.

Electron Probe Microanalysis (EPMA)

After heat treatment, the specimens were polished to a $1 \mu \mathrm{m}$ finish using traditional metallographic techniques. Concentration maps of $\mathrm{Al}, \mathrm{Co}, \mathrm{Cr}, \mathrm{Ni}, \mathrm{Re}, \mathrm{Ta}, \mathrm{Ti}$ and $\mathrm{W}$ were then obtained from each of the samples using a Cameca SX50 electron probe microanalyser (EPMA), in the following way. Measurements were made over a $1000 \mu \mathrm{m}$ by $1000 \mu \mathrm{m}$ square mesh at a spacing of $50 \mu \mathrm{m}$. The wavelength dispersive spectrometers (WDS) which were employed were equipped with crystals of TAP (used for $\mathrm{Al}, \mathrm{Ta}$ and Re), PET (used for Ti, Mo and W) and LIF (11sed for Cr, Co and Ni) [13]. Xray counts were recorded simultaneously for $\mathrm{K} \alpha$ (Al, Co, $\mathrm{Cr}, \mathrm{Ti}), \mathrm{K} \beta(\mathrm{Ni}), \mathrm{L} \alpha(\mathrm{Mo}), \mathrm{M} \alpha(\mathrm{Ta}, \mathrm{W})$ and $\mathrm{M} \beta$ radiations. These were converted to concentration values using standard correction procedures $[13,14]$ and signals from pure-element standards, except for $\mathrm{Al}$ for which an $\mathrm{Al}_{2} \mathrm{O}_{3}$ standard was used. The acceleration voltage, beam current and take-off angle for the analyses were $20 \mathrm{kV}, 100 \mathrm{nA}$ and $40^{\circ}$ respectively and the counting time for each point was approximately $72 \mathrm{~s}$.

Because of the nature of the analysis carried out, it became appropriate to characterise the microsegregration in the asreceived, as-cast CMSX-4 with greater spatial resolution. For this purpose a $1000 \mu \mathrm{m}$ by $1000 \mu \mathrm{m}$ square mesh was used and data were collected at a resolution of $4 \mu \mathrm{m}$.

\section{Differential Scanning Calorimetry}

A Stanton-Redcroft model DSC1500 was employed for the measurements. To avoid sample contamination, sapphire crucibles were placed inside platinum ones. Cylindrical samples of $3.5 \mathrm{~mm}$ diameter and $2 \mathrm{~mm}$ thickness were found to yield an acceptable signal/noise ratio. The measurements were conducted at a cooling rate of $10^{\circ} \mathrm{C} /$ min under an atmosphere of scrubbed argon. The measurement range was $1500^{\circ} \mathrm{C}$ to $500^{\circ} \mathrm{C}$. The reference pan had a similar arrangement of a sapphire crucible within a platinum one; runs were carried out with the reference pan empty, and also with a specimen of $\alpha$-alumina of known mass and heat capacity. The specific heat capacity of the CMSX-4 sample was then determined using the ratio method, as described in [15]. Conversion of the data for specific heat capacity vs temperature to fraction solid vs temperature was carried out using a geometrical method [16]. 


\section{Optical and Scanning Electron Microscopies}

For the purposes of optical microscopy, the polished samples were etched in a mixture of $100 \mathrm{ml}$ nitric acid, $500 \mathrm{ml}$ hydrochloric acid, $25 \mathrm{~g}$ ferric chloride, $25 \mathrm{~g}$ cupric chloride and $400 \mathrm{ml}$ water. It was found that this gave satisfactory contrast from the eutectic regions. Optical micrographs were taken with a Zeiss Axiotech reflecting light microscope using polarisation contrast.

In order to estimate the volume fraction of the eutectic mixture, use was made of a. JEOL 6340 field-emission gun scanning electron microscope (FEGSEM); to minimise errors associated with the subsequent stereological analysis, backscattered electron signals were used. Digital image micrographs were taken with a magnification of 10,000 using $512 \times 512$ pixels, thus achieving a resolution of $\sim 0.02 \mu \mathrm{m}$ per pixel. Subsequently, the micrographs were subjected to inage analysis using a commercial innage analysis software package (Kontron Elektronik KS300 version 2.00).

\section{Determination of Interdiffusion Coefficients and Atomic Mobilities}

To make predictions of the rate of homogenisation of ascast CMSX-4, it became necessary to make measurements of the interdiffusion coefficients in a number of model binary and ternary diffusion couples. Special emphasis was placed on the Ni-Re, Ni-W, Ni-Ta and Ni-Al-Ti systems. Diffusion couples were fabricated from high purity constituents which had been specially prepared using vacuum induction melting; bonding was achieved using a ThermecMaster- $Z$ thermo-mechanical simulator [5]. These were heat-treated in a vacuum furnace for various times at temperatures between $1000^{\circ} \mathrm{C}$ and $1300^{\circ} \mathrm{C}$. Electron probe microanalysis was then used to determine the extent of interdiffusion, and interdiffusion coefficients determined using a modified form of the Boltzmann-Matano analysis, following [5]. Values of the interdiffusion coefficients for $\mathrm{Ni}-\mathrm{Mo}$ were estimated from $[17,18]$ and for Ni-Co from $[19,20]$. For modelling purposes, atomic mobilities were evaluated using the method reported in [21], with care being taken to ensure consistency with a databank of thermodynamic parameters for the superalloys [22]. The mobilities given by Engstrom \& Agren [23] for the ternary Ni-Cr-Al system were accepted. The expressions are tabulated in the Appendix. Figure 1 illustrates the way in which the interdiffusion coefficients in nickel vary as a function of temperature, for a number of elements pertinent to the superalloys.

\section{Experimental Results and Analysis}

On the Morphology and Scale of Dendritic Microstructure

In Figure 2, the morphology and scale of the dendritic structure on (a) transverse and (b) longitudinal sections is illustrated. Consistent with observations reported elsewhere [24-27], for this class of material and for the casting conditions used in a typical commercial investment casting foundry [12] the primary dendrite arm spacing $L_{p}$ lies in the

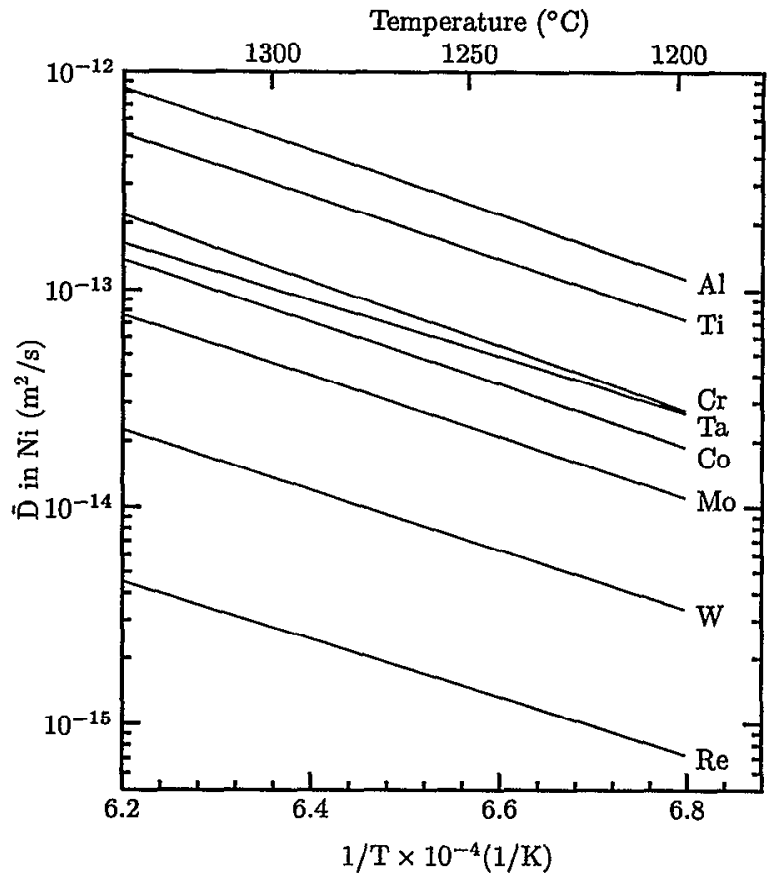

Figure 1: Variation of the interdiffusion coefficient in pure nickel of various elements pertinent to the superalloys, as a function of inverse temperature.

range $100 \mu \mathrm{m}$ to $500 \mu \mathrm{m}$. The secondary $\operatorname{arm}$ spacing $L_{s}$ is in the range $30 \mu \mathrm{m}$ to $50 \mu \mathrm{m}$.

On the Microsegregation in CMSX-4 in the As-Cast Condition

Maps of local concentration, as determined on a transverse section using electron probe microanalysis, are given in Figure 3. It has been found that the elements $\mathrm{Co}, \mathrm{Cr}, \mathrm{Re}, \mathrm{W}$ partition to the dendrite cores with $\mathrm{Al}, \mathrm{Ni}, \mathrm{Ta}$, Ti segregating to the interdendritic regions. It is notable that the heavy elements Re, Ta and W segregate particularly strongly. For various reasons it is of interest to quantify the equilibrium partitioning ratios from the EPMA data. This can be done by assuming that no diffusion occurs in the solid during solidification and subsequent cooling, that the extent of undcrcooling is small, and that therc is no macrosegregation [28]. The partitioning ratio of each component is then given by the ratio of the composition at the dendrite core to the mean composition determined. However, in our experience, the estimation of the chemical composition at the dendrite core requires some care because of the possible presence of statistical noise in the EPMA data, particularly when a large amount has been collected. It is helpful to have a procedure which helps with this situation.

For this reason we have adapted the statistical technique of Gungor [29], which was originally applied to binary alloys, to estimate the solidification path and thus the composition of the first solid to form. In a multicomponent alloy such as CMSX-4 there are several independent compositional variables and therefore one needs to make a decision concerning 


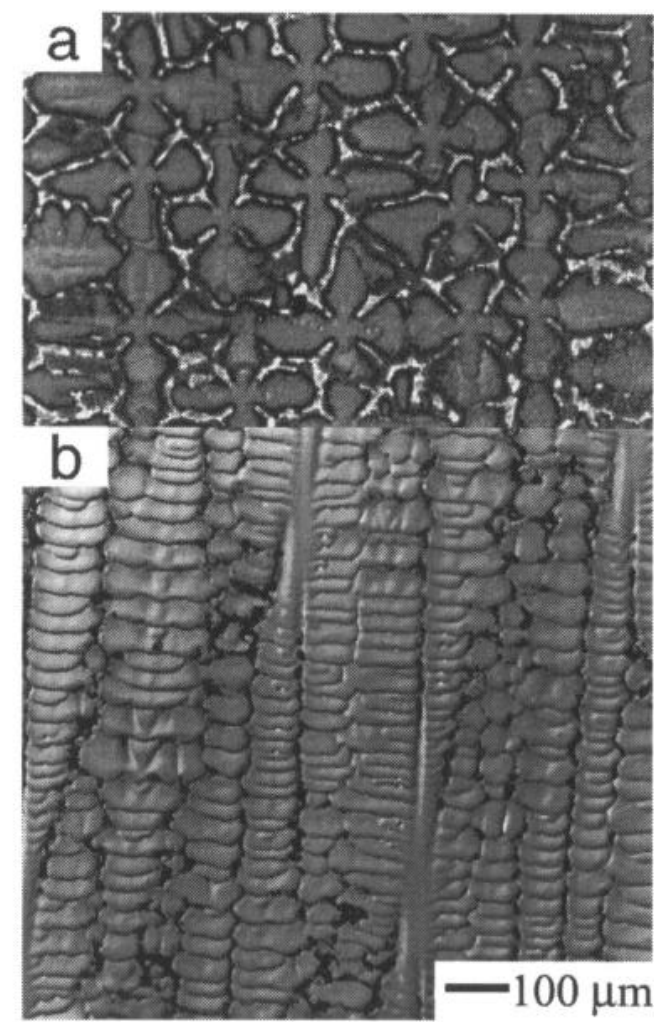

Figure 2: Optical micrograph of the as-cast structure of CMSX-4: (a) transverse section and (b) longitudinal section.

how to proceed. In the present case it is clear that Re and Ta segregate in different directions, so that the magnitude of the quantity $\left(C_{\mathrm{Ta}}-C_{\mathrm{Re}}\right)$ can be used as a basis for estimating the solid fraction $f_{s}$ to which it corresponds. A criterion based upon the Ta and Re concentrations is further supported by predictions made using a database of thermodynamic parameters [22], which indicate that the composition of these elements changes monotonically with increasing fraction of solid, even past the eutectic temperature, see the following section. The procedure employed [30] involves (i) the sorting of the datapoints into ascending order on the basis of the local value of $\left(C_{\mathrm{Ta}}-C_{\mathrm{Re}}\right)$, (ii) the assignment of an integer $i$ lying between unity and $\mathrm{N}$ on this basis, where $N$ is the number of datapoints collected, and the quantity $f_{s}$ placed equal to $(i-1) /(N-1)$ which is assumed to equate to the fraction solidified at this point and (iii) the computation of mean concentration values within intervals of $f_{s}$ corresponding to 0.02 , and the corresponding errors which are quoted as one standard deviation in the mean.

The concentrations of $\mathrm{Re}, \mathrm{Ta}, \mathrm{Ti}$ and $\mathrm{W}$ as a function of solid fraction $f_{s}$ obtained in this way are given in Figure 4. The composition profiles are well behaved in the limit of zero $f_{s}$ and this allows the composition of the first solid to form, and hence the partitioning ratios, to be estimated. The values determined in this way are listed in Table II. There is
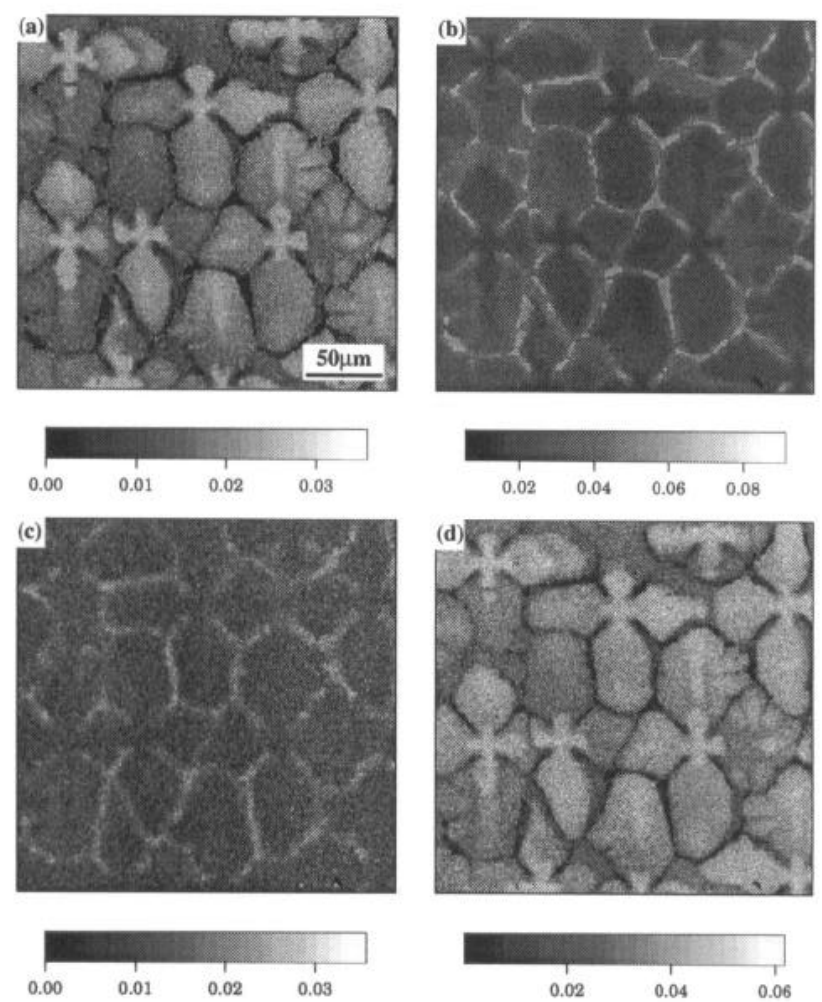

Figure 3: EPMA composition maps illustrating the interdendritic microsegregation in CMSX-4 in the as-cast condition, (a) Re, (b) Ta, (c) Ti and (d) W. Compositions expressed as weight fractions.

reasonably good agreement between the values found here, and values reported elsewhere $[31,32]$. However, there is some discrepancy for $\mathrm{Cr}$ - for this element a partitioning coefficient $k$ greater than unity was found here whereas other reported values are less than unity. The experiments reported by Ma \& Grafe [32] employed liquid metal cooling and the directional solidification/quench (DSQ) method, so that the extent of any backdiffusion is likely to be much smaller than observed here; nevertheless any backdiffusion occurring in the present case would serve to increase our values of $k$, see Figure 4 and thus this effect cannot be used to explain this discrepancy.

Table II Equilibrium partitioning ratios determined for CMSX-4. The experimental values are determined at $1 \mathrm{wt} \%$ solid, the calculated values at the liquidus temperatures.

\begin{tabular}{ccccccccl}
\hline Al & Co & Cr & Mo & Re & Ta & Ti & W & Method \\
\hline 0.86 & 1.08 & 1.05 & 0.86 & 1.66 & 0.67 & 0.86 & 1.31 & Experimental $^{\dagger}$ \\
0.91 & 1.11 & 0.92 & 0.68 & 1.62 & 0.56 & 0.69 & 1.18 & Calculated $^{\ddagger}$
\end{tabular}

${ }^{\dagger}$ Calculated at $1 \mathrm{wt} \%$ solid

${ }^{\ddagger}$ Calculated at liquidus temperature 

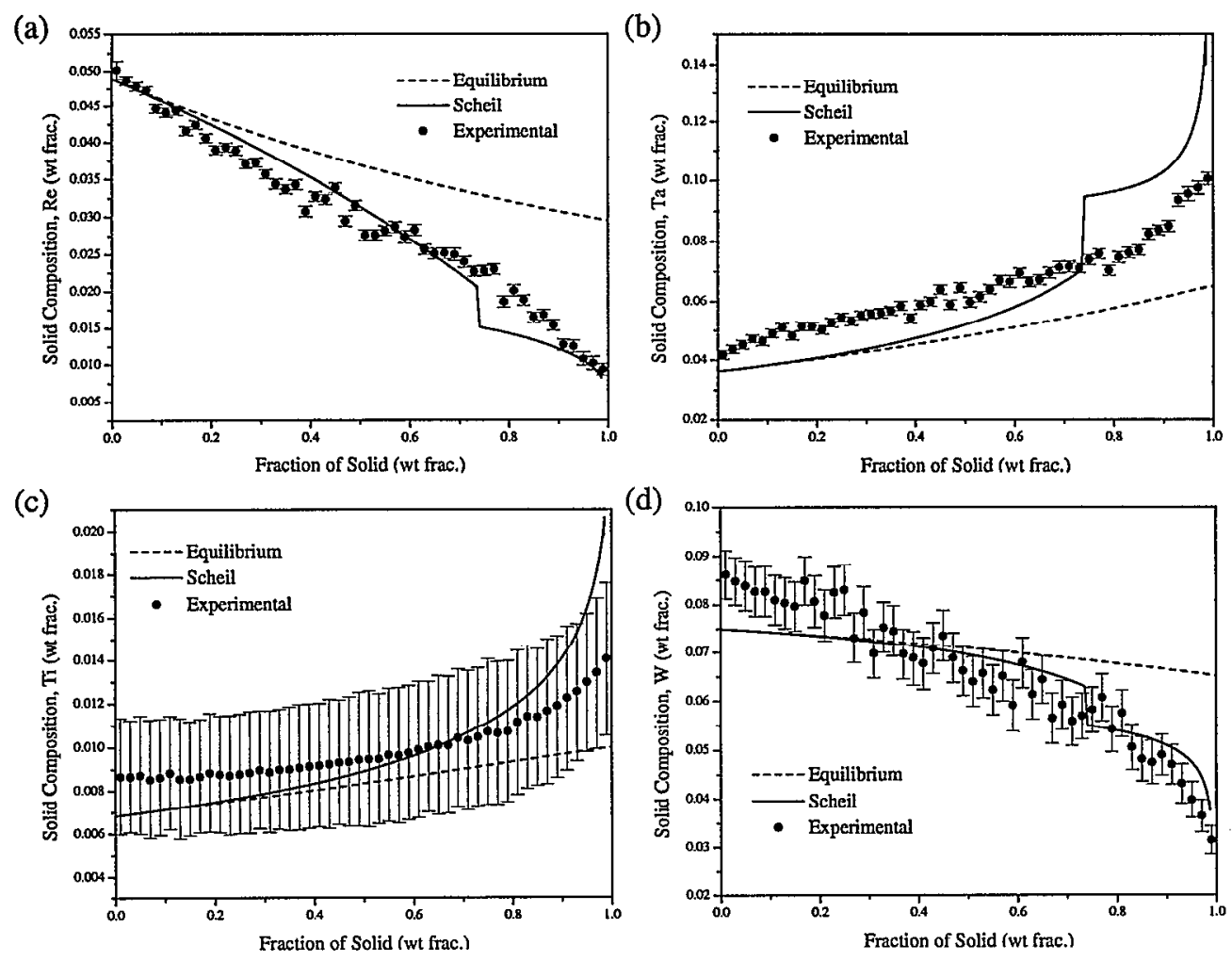

Figure 4: Solidification paths estimated by the statistical analysis of the EPMA data: (a) Re, (b) Ta, (c) Ti and (d) W. Also shown are the curves calculated using the equilibrium and Gulliver-Scheil assumptions.
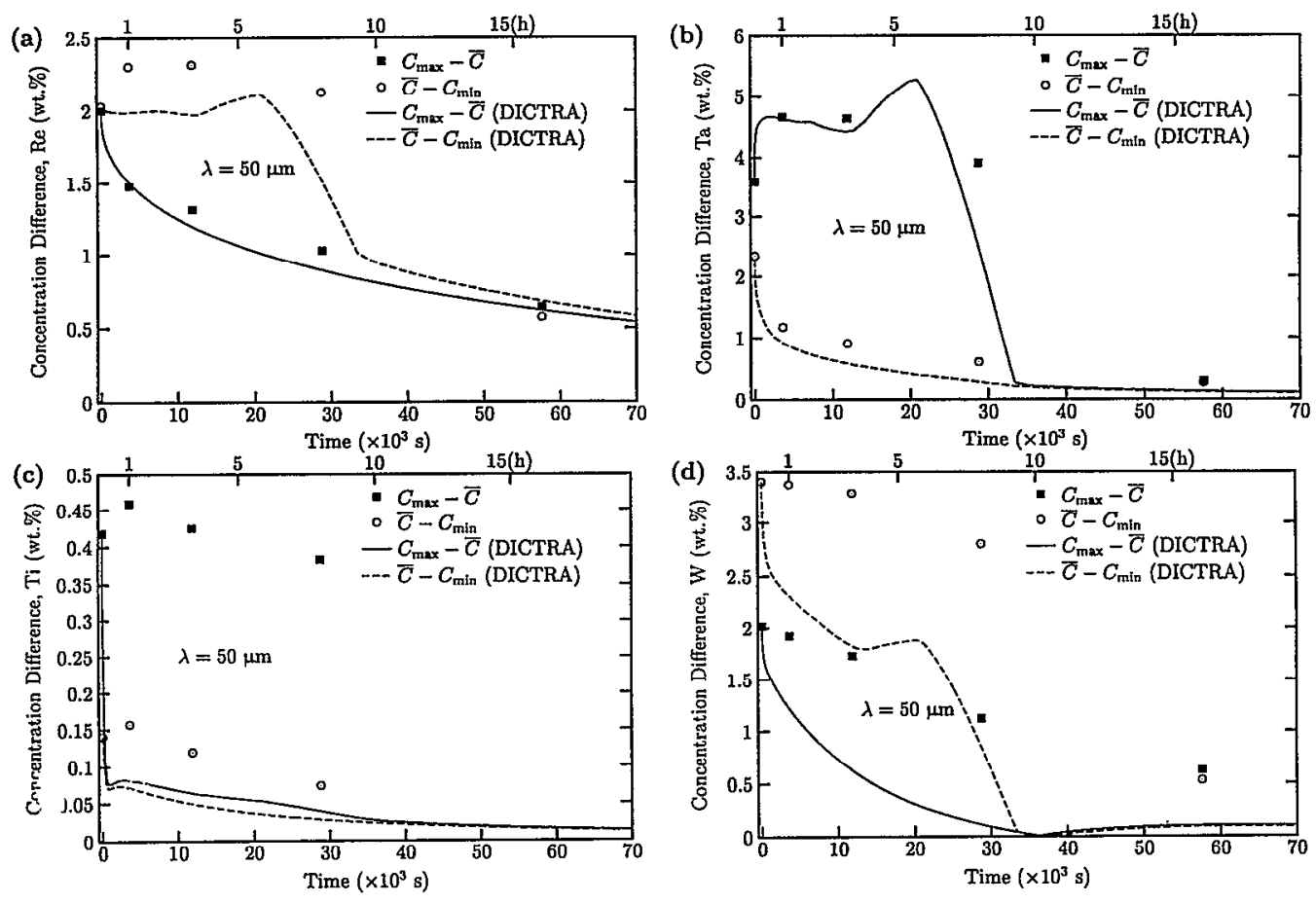

Figure 5: Variation of the quantities $\left(C_{\max }-\bar{C}\right)$ and $\left(\bar{C}-C_{\min }\right)$, during heat treatment at $1315^{\circ} \mathrm{C}$ : (a) Re, (b) $\mathrm{Ta}$, (c) $\mathrm{Ti}$ and (d) W. Values predicted by the numerical model are also shown. 


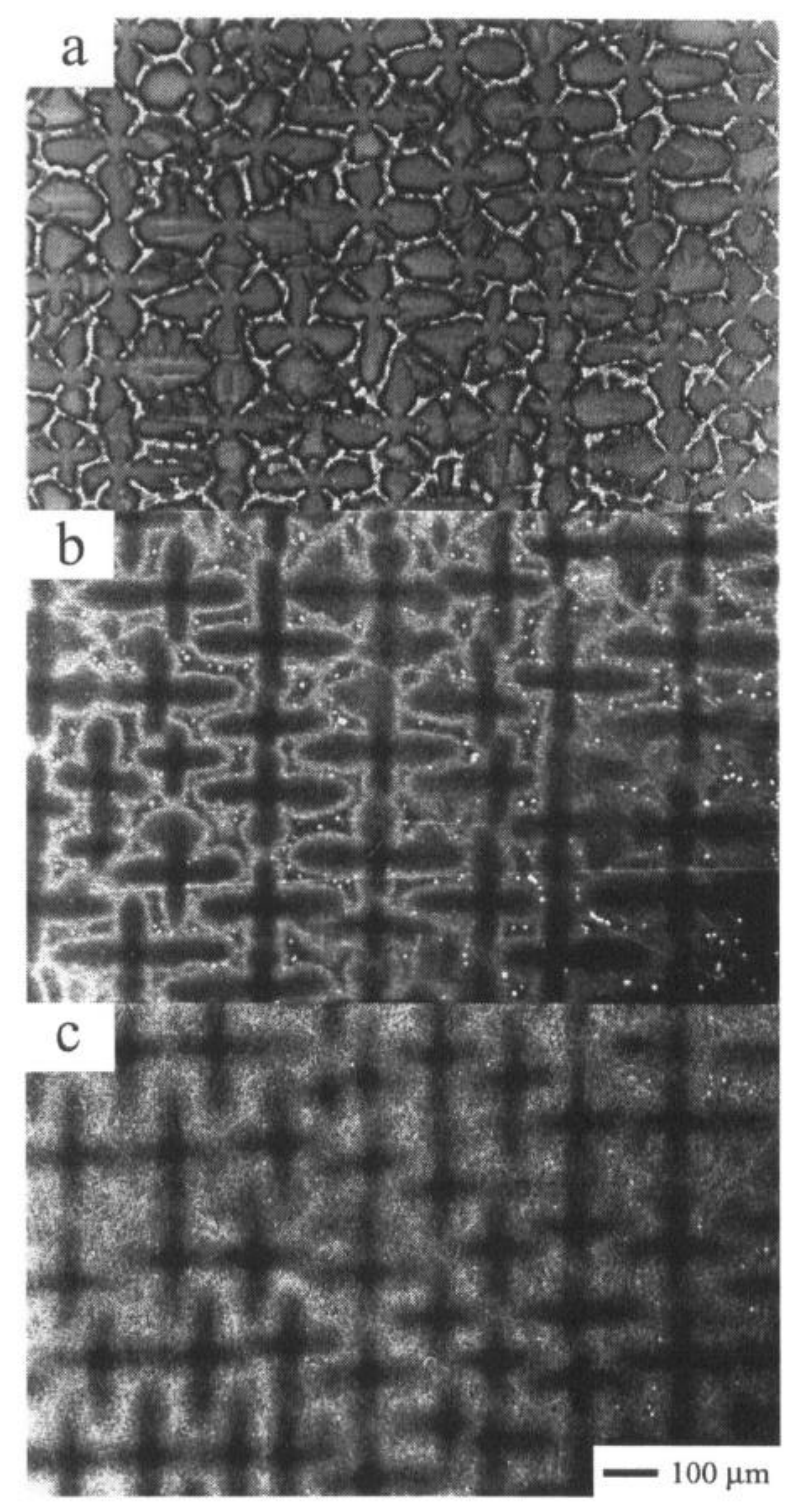

Figure 6: Optical micrographs illustrating the microstructure of as-cast CMSX-4, and its evolution during heat treatment at $1315^{\circ} \mathrm{C}$ : (a) as-cast, (b) after 9 hours and (c) after 12 hours.

\section{On the Homogenisation of Microsegregation in CMSX-4}

We have found that the microsegregation which is inherited from the casting process, see Figure 3, and its subsequent homogenisation cannot be represented adequately by Equation 1 . This can be seen most readily by examining the quantities $\left(C_{\max }-\bar{C}\right)$ and $\left(\bar{C}-C_{\min }\right)$, where $C_{\max }, C_{\min }$ and $\bar{C}$ correspond to the maximum, minimum and average compositions seen on the solidification profiles; on Figure 5 these are the values corresponding to time zero. For CMSX4 , one can see that the quantities $\left(C_{\max }-\bar{C}\right)$ and $\left(\bar{C}-C_{\min }\right)$ differ significantly in magnitude. A further point concerns the rate at which the dendritic and interdendritic regions homogenise. Our data demonstrate beyond any reasonable doubt that the dendrite cores homogenise more rapidly than the interdendritic regions. For some of the elements in the interdendritic region and particularly $\mathrm{Ta}$, the composition rises at first, before falling again as homogenisation proceeds still further - thus there is evidence of the occurrence of up-hill diffusion. This behaviour requires further rationalisation.

Observations made on the eutectic mixture in the as-cast condition have indicated that it consists of a mixture of the $\gamma$ and $\gamma^{\prime}$ phases, see Figure 6. Figure 7 shows how the fraction of the eutectic mixture evolves during heat treatment at $1315^{\circ} \mathrm{C}$.

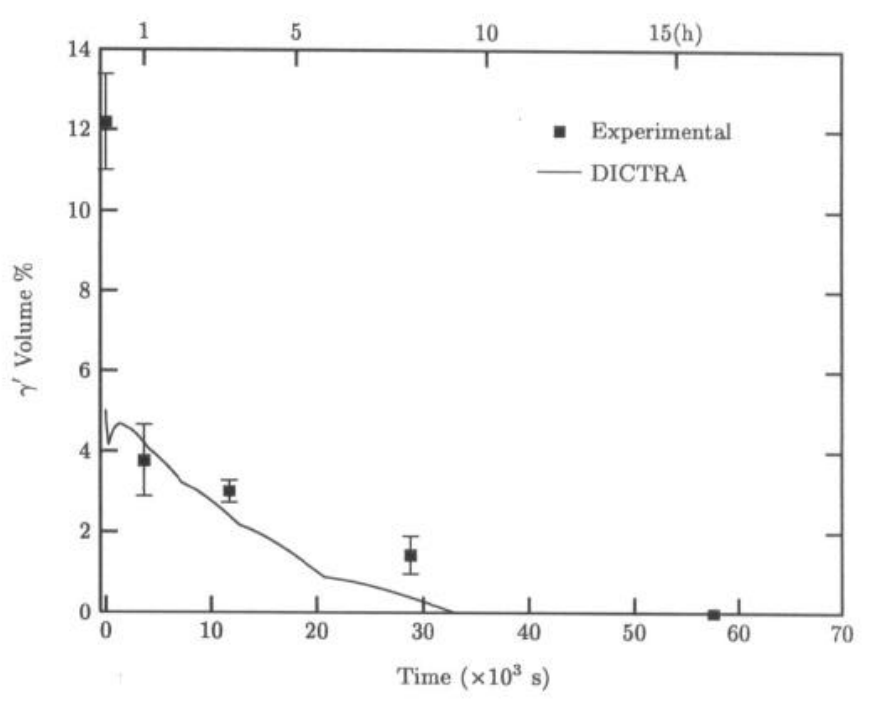

Figure 7: Variation of the fraction of coarse $\gamma^{\prime}$ in the eutectic mixture with time and temperature during heat treatment, as determined using image analysis. Values predicted by the numerical model are also shown.

\section{Simulation of Microstructure Evolution}

Modelling of the Evolution of Microsegregation

The experimentally determined solidification paths given in Figure 4 have been compared with the predictions made using the Thermocalc software [33] and a database of thermodynamic parameters [22]. For the purposes of the present analyses, one assumes that only the liquid, $\gamma$ and $\gamma^{\prime}$ phases play a part in the reaction. On Figure 4 the equilibrium lines are shown, as are the lines predicted by the GulliverScheil approach, determined using the temperature stepping scheme suggested by Sundman \& Ansara [34]. Once the eutectic temperature is passed, the composition quoted corresponds to the weighted average of those corresponding to the $\gamma$ and $\gamma^{\prime}$ phases, it being assumed that the EPMA method is incapable of resolving the compositions of the $\gamma$ and $\gamma^{\prime}$ phases in the eutectic mixture.

From Figure 4 it can be seen that the models reproduce the observed sign of partitioning reasonably well. From the 


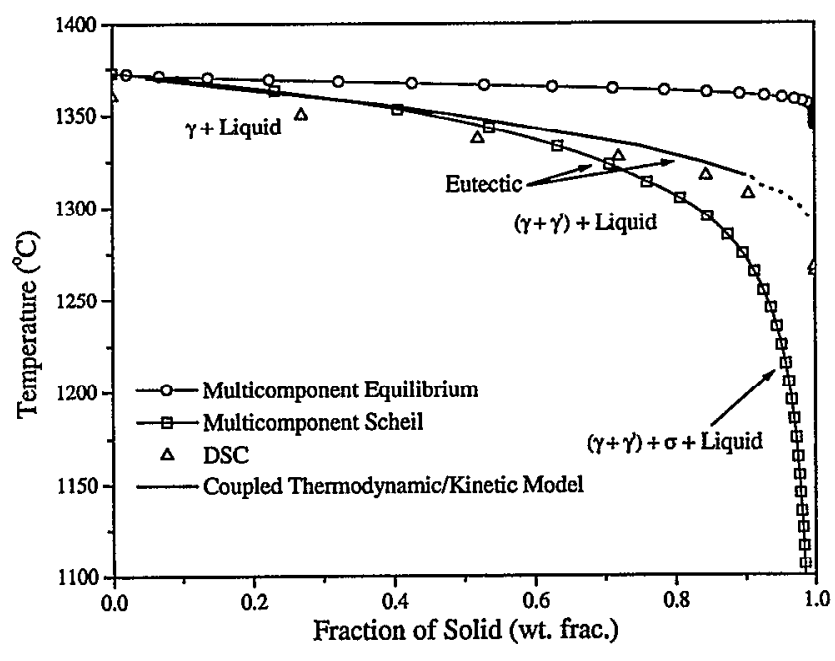

Figure 8: Variation of the solid fraction with temperature, as determined from the DSC measurements and from the numerical models.

composition of the first solid to form, one can see that the initial partitioning coefficients are also predicted reasonably, with the exception of $W$. However, the predictions at temperatures lower than the eutectic point are in rather poor agreement with experiment, with the sharp change in composition predicted by the database as the consequence of the eutectic reaction liquid $\rightarrow \gamma+\gamma^{\prime}$ not being observed. This is probably a consequence of the limitations of the experimental techniques and the analysis method which has been employed.

From an examination of the data in Figure 4, it is not easy to confirm whether or not there is significant occurrence of back-diffusion during solidification. A better way of testing this to examine the manner in which the fraction of solid evolves with decreasing temperature, see Figure 8 , as determined using differential scanning calorimetry. The solidification range predicted by the Gulliver-Scheil model is too wide and this proves conclusively that back-diffusion is indeed occurring.

\section{Modelling of Homogenisation during Heat Treatment}

The solution heat treatment of CMSX-4 has been simulated using the DICTRA software [e.g. 35] and the database of kinetic parameters given in the Appendix. All simulations have been made using the model for dispersed systems [36]. The labyrinth factor was taken to be unity. Thus long-range diffusion in the continuous matrix phase $\gamma$ is accounted for. The formation and dissolution of dispersed phases $\gamma^{\prime}$ and liquid is allowed, but diffusion within them is not permitted. Hence, it is assumed that significant gradients in chemical potential exist only over distances much greater than the inter-particle spacing, with mass transport occurring in one dimension and planar co-ordinates. The phases in any given volume element are taken to be in local equilibrium and hence their constitution at any given time during the simulation is estimated by solving the phase diagram problem [37]. The initial composition profiles representing the as-cast microsegregation were obtained from the statistical analysis described earlier, see Figure 4 . Since this analysis does not yield a length scale, a planar region of $50 \mu \mathrm{m}$ length has been assumed, which approximates to the secondary dendrite arm spacing, see Figure 2. The timestep $\Delta t$ for the calculations was $0.5 \mathrm{~s}$.

The results of the simulations are presented in Figure 5, for heat treatment at $1315^{\circ} \mathrm{C}$ which is approximately equal to the equilibrium solvus temperature of the alloy. Although the agreement is not perfect, one can see that the coupled thermodynamic/kinetic model accounts for the different homogenisation rates of dendritic and interdendritic regions, but also for the enrichment of the interdendritic regions with respect to $\mathrm{Ta}$ which occurs within the first few hours of heat treatment. This effect occurs because the interdendritic region forms at a temperature different from that al which heat treatment is performed; thus bulk mass transport by diffusion can occur giving rise to enrichment of interdendritic $\gamma^{\prime}$ by elements such as Ta. Quite clearly, the sinusoidal form implied by Equation 1 is valid only after these effects have occurred, about 10 hours. Unfortunately, the agreement between experiment and theory for $\mathrm{Ti}$ and $\mathrm{W}$ is not good, and this is probably because of tertiary interaction parameters which are not presently accounted for. On the other hand we have observed that the dissolution of the coarse $\gamma^{\prime}$ found in the eutectic mixture correlates well with the fraction of $\gamma^{\prime}$ predicted by the model, see Figure 7 . The predictions of the rate of homogenisation at temperatures below the solvus are also in reasonable agreement with experiment, see Figure 9. It should be noted that the model is also capable of predicting the onset of incipient melting, i.e. the formation of interdendritic liquid and its subsequent resolidification as homogenisation progresses.

\section{Summary and Conclusions}

The following conclusions can be drawn from this work:

1. A statistical treatment of electron probe microanalysis data has been proposed, which appeals to the local value of the quantity $\left(C_{\mathrm{Ta}}-C_{\mathrm{Re}}\right)$. The method allows the solidification path, the composition of the first solid to form and the partition coefficients to be estimated.

2. In CMSX-4 superalloy, the elements $\mathrm{Co}, \mathrm{Cr}, \mathrm{Re}, \mathrm{W}$ segregate to the dendrite cores with $\mathrm{Al}, \mathrm{Ni}, \mathrm{Ta}, \mathrm{Ti}$ partitioning to the interdendritic regions. It is notable that the heavy elements $\mathrm{Re}$, Ta and $\mathrm{W}$ segregate particularly strongly. Some inconsistencies between theory and experiment have been noted.

3. By appealing to a database of thermodynamic parameters for the superalloys and the results from differential scanning calorimetry, it has been shown that the solidification path cannot be explained without acknowledging that some backdiffusion occurs during solidification. 

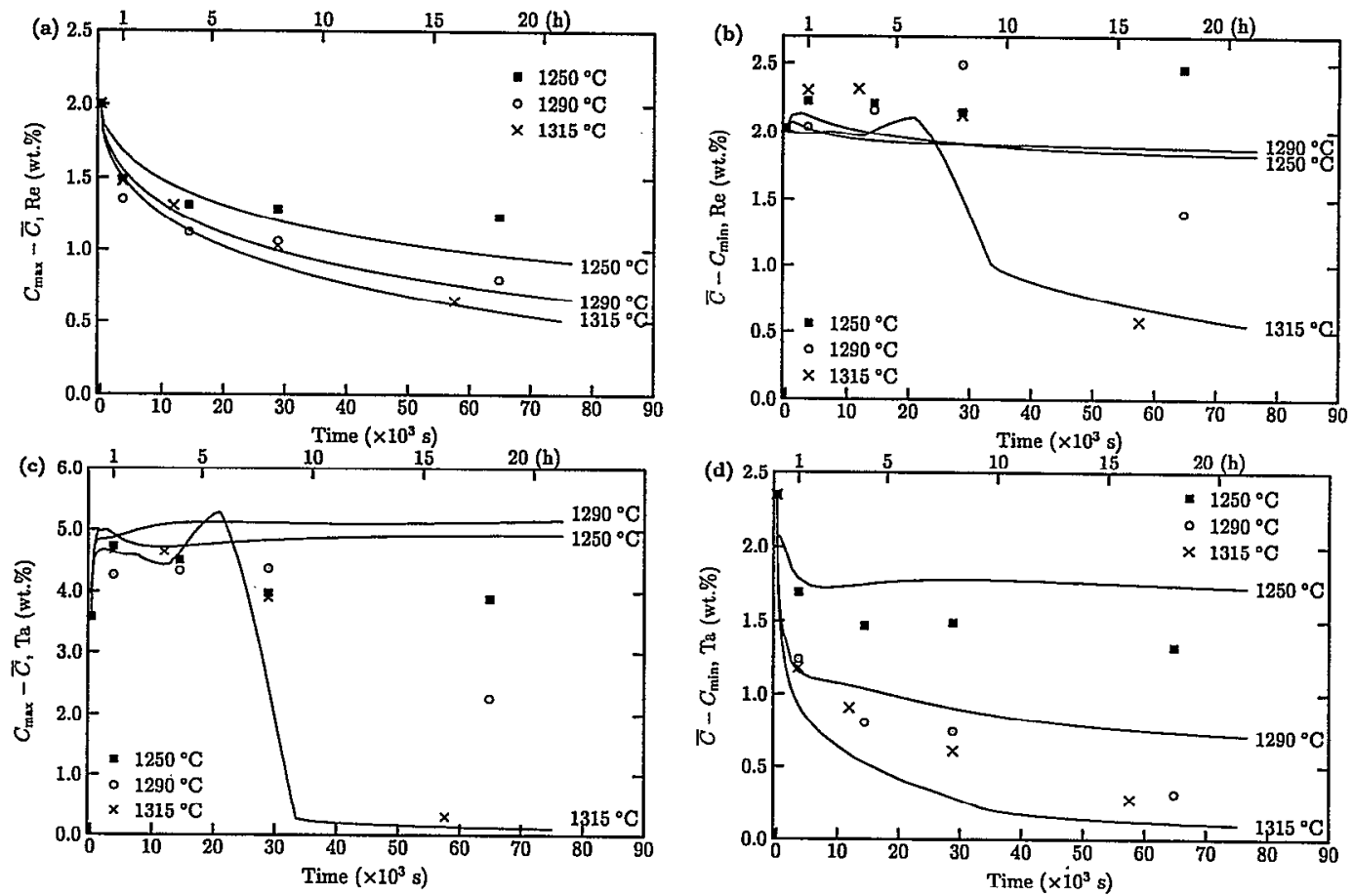

Figure 9: Response of the interdendritic segregation to heat treatment, (a) variation of $\left(C_{\max }-\bar{C}\right)$ for $\operatorname{Re},(\mathrm{b})$ variation of $\left(\bar{C}-C_{\min }\right)$ for $\mathrm{Re},(\mathrm{c})$ variation of $\left(C_{\max }-\bar{C}\right)$ for Ta, (b) variation of $\left(\bar{C}-C_{\min }\right)$ for Ta. Values predicted by the numerical model are also shown.

4. During solution heat treatment, the dendritic and interdendritic regions homogenise at different rates. Enrichment of some solutes, e.g. Ta, Co and $\mathrm{Cr}$ occurs in the eutectic region. Simple expressions which are based upon a sinusoidal variation of composition are unable to account for these effects. More complicated theory is required.

6. Kinetic parameters pertinent to the superalloys have been coupled with the thermodynamic parameters, so that the diffusion of solutes during homogenisation can be handled. It has been shown that the simulations are in reasonable agreement with the observations.

7. The model has reached the point where it can make a useful contribution to the process of alloy design, e.g. for the assessment of new superalloy compositions and for the design of appropriate heat treatments. However, more work needs to be carried out to better establish some of the thermodynamic and kinetic parameters required.

\section{Acknowledgements}

The authors thank the Cambridge Commonwealth Trust, the Engineering \& Physical Sciences Research Council (EPSRC), Rolls-Royce plc and the Defence Evaluation \& Research Agency (DERA) for sponsoring this work. The assistance of Dr.S.J.B. Reed with the EPMA analysis is gratefully acknowledged. Helpful discussions with Colin Small (Rolls-Royce), and Mike Henderson \& Mike Winstone
(DERA) are much appreciated. It is a pleasure to acknowledge the help and advice of Lindsay Chapman and Peter Quested of the National Physical Laboratory.

\section{$\underline{\text { References }}$}

1. The Jet Engine, (The Technical Publications Department, Rolls-Royce plc, Derby, UK, Fourth Edition, 1992).

2. F.R.N. Nabarro and H.L. de Villiers, The Physics of Creep, (Taylor and Francis, 1995).

3. M. McLean, "Nickel-Base Superalloys: Current Status and Potential", Philosophical Transactions of the Royal Society London A, 351, (1995), 419-433.

4. R.D. Kissinger, D.J. Deye, D.L. Anton, A.D. Cetel, M.V. Nathal, T.M. Pollock and D.A. Woodford, eds., Superalloys 1996, (The Minerals, Metals and Materials Society, Warrendale, Pennsylvania, USA, 1996).

5. M.S.A. Karunaratne, P. Carter and R.C. Reed, "Interdiffusion in the Face-Centred-Cubic Phase of the Ni-Re, $\mathrm{Ni}-\mathrm{Ta}$ and $\mathrm{Ni}-\mathrm{W}$ Systems between 900 and $1300^{\circ} \mathrm{C}$ ", Materials Science and Engineering, A281 (2000), 229-233.

6. J.K. Tien and V.C. Nardone, "The US Superalloys Industry - Status and Outlook", Journal of Mctals, 36 (1984), 52-57.

7. M. Durand-Charre, The Microstructure of Superalloys, (Gordon \& Breach Science Publishers, Amsterdam, The Netherlands, 1997). 
8. G.R. Purdy and J.S. Kirkaldy, "Homogenisation by Diffusion", Metallurgical Transactions, 2 (1971), 371378.

9. M. McLean, Directionally Solidified Materials for High Temperature Service, (The Metals Society, London, 1983).

10. R.G. Ward, "Effect of Annealing on the Dendritic Segregation of Manganese in Steel", Journal of the Iron and Steel Institute, 203 (1965), 930-932.

11. F. Weinberg and R.K. Buhr, "Homogenisation of a Low-Alloy Steel", Journal of the Iron and Steel Institute, 207 (1969), 1114-1121.

12. P. Carter, D.C. Cox, Ch.-A. Gandin and R.C. Reed, "Process Modelling of the Grain Selection during Solidification of Superalloy Single Crystal Castings", Materials Science and Engineering, A280 (2000), 233246.

13. S.J.B. Reed, Electron Microprobe Analysis, (Cambridge University Press, Cambridge, Second Edition, 1993).

14. J.L. Pouchou and F. Pichoir, Proceedings of the 11th International Congress on X-ray Optics and Microanalysis, J.D. Brown and R.H. Packwood, eds., (London, 1996).

15. M.P. Jackson, M.J. Starink and R.C. Reed, "Determination of the Precipitation Kinetics of $\mathrm{Ni}_{3} \mathrm{Al}$ in the NiAl System using Differential Scanning Calorimetry", Materials Science and Engineering, A264 (1999), 2638.

16. L. Chapman and P. Quested, National Physical Laboratory, Teddington, Middlesex, UK, Private Communication.

17. A. Davin, V. Leroy, D. Coutsouradis and L. Habraken, "Comparison of the Diffusion of Some Substitution Elements in Nickel and Cobalt", Cobalt, 19 (1963), 51-56.

18. C.P. Heijwegan and G.D. Rieck, "Diffusion in the Mo$\mathrm{Ni}, \mathrm{Mo}-\mathrm{Fe}$ and Mo-Co Systems", Acta metallurgica, 22 (1974), 1269-1281.

19. T. Ustad and H. Sorum, "Interdiffusion in the Fe-Ni, $\mathrm{Ni}-\mathrm{Co}$ and Fe-Co Systems", Physica Status Solidi, 20A (1973), 285-294.

20. A.B. Vladimirov, V.N. Kaygorodov, S.M. Klotsman and I.Sh. Trkhtenberg, "Bulk Diffusion of Cobalt and Tungsten in Nickel", Physics of Metals and Metallography, 46 (1978), 94-101.

21. B. Jonsson, "Assessment of the Mobilities of $\mathrm{Cr}, \mathrm{Fe}$ and $\mathrm{Ni}$ in Binary $\mathrm{Cr}-\mathrm{Fe}$ and $\mathrm{Cr}-\mathrm{Ni}$ Alloys", Scandinavian Journal of Metallurgy, 24 (1995), 21-27.

22. N. Saunders, "Phase Diagram Calculations for High Temperature Structural Materials", Philosophical Transactions of the Royal Society of London A, 351 (1995), 543-561.

23. A. Engstrom and J. Agren, "Assessment of Diffusional Mobilities in Face-centered Cubic Ni-Cr-Al Alloys", Zeitschrift für Metallkunde, 87 (1996), 92-97.
24. J. Glownia and A. Janas, "Microsegregation in Den-

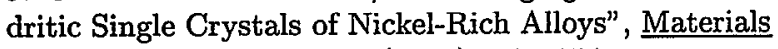
Science and Technology 3 (1987), 149-154.

25. V.A. Wills and D.G. McCartney, "A Comparative Study of Solidification Features in Nickel-base Superalloys: Microstructural Evolution and Microsegregation", Materials Science and Engineering, A145 (1991), 223-232.

26. S.N. Tewari, M. Vijayakumar, J.E. Lee and P.A. Curreri, "Solutal Partition Coefficients in Nickel-base Superalloy PWA-1480", Materials Science and Engineering, A141 (1991), 97-102.

27. D. Ma and P.R. Sahm, "Untersuchung des Erstarrungsvorgangs der gerichtet erstarrten Superlegierung CMSX-6", Zeitschrift für Metallkunde, 87 (1996), 640644.

28. P.K. Sung and D.R. Poirier, "Liquid-Solid Partition Ratios in Nickel-base Alloys", Metallurgical and Materials Transactions, 30A (1999), 2173-2181.

29. M.N. Gungor, "A Statistically Significant Experimental Technique for Investigating Microsegregation in Cast Alloys", Metallurgical and Materials Transactions, $20 \mathrm{~A}$ (1989), 2529-2533.

30. D.C. Cox, "Characterisation of the Microstructural Evolution in Single Crystal Nickel-Base Superalloys", (Ph.D Thesis, The University of Cambridge, 2000).

31. N. D'Souza, B.A. Shollock and M. McLean, "Quantitative Characterisation of Micro-segregation and Competitive Grain Growth in CMSX-4", Solidification Processing 1997, J. Beech and H. Jones, eds., (Department of Engineering Materials, University of Sheffield, UK, 1997), 316-320.

32. D. Ma and U. Grafe, "Microsegregation in Directionally Solidified Dendritic-Cellular Structure of Superalloy CMSX-4", Materials Science and Engineering, A270 (1999), 339-342.

33. THERMO-CALC, see for example, B. Sundman, Report D53, Summary of the Modules of Thermo-calc, (The Royal Institute of Technology, Stockholm, Sweden, 1984).

34. B. Sundman and I. Ansara, The SGTE Casebook, K. Hack, ed., (The Institute of Metals, London, UK, 1996), 94-98.

35. J.O. Andersson, L. Hoglund, B. Jonsson and J. Agren, in Fundamentals and Applications of Ternary Diffusion, G.R. Purdy, ed., (Pergawun Press, New York 1990), 153-163.

36. A. Engstrom, L. Hoglund and J. Agren, "Cowputer Simulation of Diffusion in Multiphase Systems", Metallurgical and Materials Transactions, 25A (1994), 1127-1134.

37. N. Matan, H.M.A. Winand, P. Carter, P.D. Bogdanoff and R.C. Reed, "A Coupled Thermodynamic/Kinetic Model for Diffusional Processes in Superalloys", Acta Materialia, 46 (1998), 4587-4600. 


\section{Appendix}

In order to perform the calculations, it is necessary to estimate the diffusional mobilities of the components in CMSX4. For simple disordered subsitutional phases such as the FCC phase, the mobility $M_{i}$ of each component $i$ can be represented by the following equation [36]

$$
M_{i}=\frac{1}{R T} \exp \left\{\frac{-\Delta G_{i}^{*}}{R T}\right\}
$$

where $R$ is the universal gas constant and $T$ the temperature. In an $n$ component system the activation energy $\Delta G_{i}^{*}$ is expanded according to

$$
\Delta G_{i}^{*}=\sum_{j=1, n}\left[x_{j} \Delta G_{i}^{* j}+1 / 2 \sum_{j, k=1, \pi(j \neq k)} x_{j} x_{k}{ }^{0} \Delta G_{i}^{* j, k}\right]
$$

where $x_{i}$ is the mole fraction of component $i$. The constants which were used in the calculations are as follows and arc in units of $\mathrm{J} / \mathrm{mol}$.

Mobility for $\mathrm{Al}$

$$
\begin{aligned}
& \Delta G_{\mathrm{Al}}^{* \mathrm{Al}}=-142000+R T \ln \left(1.71 \times 10^{-4}\right) \\
& \Delta G_{\mathrm{Al}}^{* \mathrm{Cr}}=-235000-82 T \\
& \Delta G_{\mathrm{Al}}^{* \mathrm{Ni}}=-284000+R T \ln \left(7.5 \times 10^{-4}\right) \\
& { }^{0} \Delta G_{\mathrm{Al}, \mathrm{Ni}}^{* \mathrm{Al}}=-41300-91.2 T \\
& { }^{0} \Delta G_{\mathrm{Al}, \mathrm{Cr}}^{* \mathrm{Al}}=335000 \\
& { }^{0} \Delta G_{\mathrm{Al}, \mathrm{Ni}}^{* \mathrm{Cr}}=-53200
\end{aligned}
$$

Mobility for Co

$$
\begin{aligned}
& \Delta G_{\mathrm{Co}}^{* \mathrm{Co}}=-276731.84-80.06 T \\
& \Delta G_{\mathrm{Co}}^{* \mathrm{Ni}}=-277380.37-74.47 T \\
& \Delta G_{\mathrm{Co}}^{* \mathrm{Al}}=-174472.80+R T \ln \left(4.64 \times 10^{-6}\right) \\
& { }^{0} \Delta G_{\mathrm{Co}}^{* \mathrm{Co} \mathrm{Ni}}=133337.99 E-66.98 T
\end{aligned}
$$

Mobility for $\mathrm{Cr}$

$$
\begin{aligned}
& \Delta G_{\mathrm{Cr}}^{* \mathrm{Cr}}=-235000-82.00 T \\
& \Delta G_{\mathrm{Cr}}^{* \mathrm{Al}}=-261700+R T \ln (0.64) \\
& \Delta G_{\mathrm{Cr}}^{* \mathrm{Ni}}=-287000-64.40 T \\
& { }^{0} \Delta G_{\mathrm{Cr}, \mathrm{Ni}}^{* \mathrm{Cr}}=-68000 \\
& { }^{0} \Delta G_{\mathrm{Cr}}^{* A \mathrm{Al}}=-487000 \\
& { }^{0} \Delta G_{\mathrm{Cr}}^{* \mathrm{Al}, \mathrm{Ni}}=-118000
\end{aligned}
$$

Mobility for Mo

$$
\begin{aligned}
& \Delta G_{\mathrm{Mo}}^{* \mathrm{Mo}}=-286273.92-56.46 T \\
& \Delta G_{\mathrm{Mo}}^{* \mathrm{Ni}}=-269133.21-84.35 T \\
& \Delta G_{\mathrm{Mo}}^{* \mathrm{Al}}=-54810.40+R T \ln \left(1.04 \times 10^{-13}\right) \\
& { }^{0} \Delta G_{\mathrm{Mo}}^{* \mathrm{Mo}, \mathrm{Ni}}=-263315.40+172.55 T
\end{aligned}
$$

Mobility for $\mathrm{Ni}$

$$
\begin{aligned}
& \Delta G_{\mathrm{Ni}}^{* \mathrm{Ni}}=-287000-69.8 T \\
& \Delta G_{\mathrm{Ni}}^{* \mathrm{Ai}}=-145900+R T \ln \left(4.40 \times 10^{-4}\right) \\
& \Delta G_{\mathrm{Ni}}^{* \mathrm{Ci}}=-272358.40-82.22 T \\
& \Delta G_{\mathrm{Ni}}^{* \mathrm{Ci}}=-235000-82.00 T \\
& \Delta G_{\mathrm{Ni}}^{* \mathrm{Mi}}=-286273.92-56.46 T \\
& \Delta G_{\mathrm{Ni}}^{* \mathrm{Ri}}=-502659-76.96 T \\
& \Delta G_{\mathrm{Ni}}^{* \mathrm{Ti}}=-235390-86.73 T \\
& \Delta G_{\mathrm{Ni}}^{* \mathrm{Ti}}=-138456.95-132.72 T \\
& \Delta G_{\mathrm{Ni}}^{* \mathrm{Wi}}=-367004-64.50 T \\
& { }^{0} \Delta G_{\mathrm{Ni}}^{* \mathrm{Ai}}=-113000165.50 T \\
& { }^{0} \Delta G_{\mathrm{Ni}}^{* \mathrm{Co}, \mathrm{Ni}}=931556.43-627.82 T \\
& { }^{0} \Delta G_{\mathrm{Ni}}^{* \mathrm{Mi}, \mathrm{Ni}}=-288170.36+91.26 T \\
& { }^{0} \Delta G_{\mathrm{Ni}}^{* \mathrm{Ni}, \mathrm{Re}}=1088526.75-702.62 T \\
& { }^{0} \Delta G_{\mathrm{Ni}}^{* \mathrm{Ni}, \mathrm{Ta}}=1211176.04-1012.01 T \\
& { }^{0} \Delta G_{\mathrm{Ni}}^{* \mathrm{Ni}, \mathrm{Ti}}=-100716.30+100.45 T \\
& { }^{0} \Delta G_{\mathrm{Ni}}^{* \mathrm{Ni}, \mathrm{W}}=-366978.97+231.48 T
\end{aligned}
$$

Mobility for Re

$$
\begin{aligned}
& \Delta G_{\mathrm{Re}}^{* \mathrm{Re}}=-502659-76.96 T \\
& \Delta G_{\mathrm{Re}}^{* \mathrm{Ni}}=-245037-127.54 T \\
& { }^{0} \Delta G_{\mathrm{Re}}^{* \mathrm{Ni}, \mathrm{Re}}=-168547.93+215.39 T
\end{aligned}
$$

Mobility for $\mathrm{Ta}$

$$
\begin{aligned}
& \Delta G_{\mathrm{Ta}}^{* \mathrm{Ta}}=-235390.00-86.73 T \\
& \Delta G_{\mathrm{Ta}}^{* \mathrm{Ni}}=-226313-109.20 T \\
& { }^{0} \Delta G_{\mathrm{Ta}}^{* \mathrm{Ni}, \mathrm{Ta}}=-629850.45+271.32 T
\end{aligned}
$$

Mobility of $\mathrm{Ti}$

$$
\begin{aligned}
& \Delta G_{\mathrm{Ti}}^{* \mathrm{Ti}}=-138456.95-132.72 T \\
& \Delta G_{\mathrm{Ti}}^{* \mathrm{Ni}}=-269267.07-68.81 T \\
& { }^{0} \Delta G_{\mathrm{Ti}}^{* \mathrm{Ni}, \mathrm{Ti}}=-260924.10+293.89 T
\end{aligned}
$$

Mobility of W

$$
\begin{aligned}
& \Delta G_{\mathrm{W}}^{* \mathrm{~W}}=-367004-64.50 T \\
& \Delta G_{\mathrm{W}}^{* \mathrm{Ni}}=-312426-64.39 T \\
& { }^{0} \Delta G_{\mathrm{W}}^{* \mathrm{Ni}, \mathrm{W}}=1089264.53-923.05 T
\end{aligned}
$$

